Rita Van Ham • Luc Van Vaeck •

Freddy Adams - Annemie Adriaens

\title{
Feasibility of analyzing molecular pigments in paint layers using TOF S-SIMS
}

Received: 1 August 2005 / Revised: 25 August 2005 / Accepted: 29 August 2005 / Published online: 1 November 2005

(C) Springer-Verlag 2005

\begin{abstract}
A first attempt to measure the molecular compositions of pigments in paintings using static SIMS was made. An investigation of pellets of pure pigments such as auripigment and verdigris allowed the detection of numerous high $\mathrm{m} / \mathrm{z}$ ions useful for molecular identification. Analysis of pigments in embedded paint fragments, on the other hand, only yielded elemental information because of charge build-up and contamination problems. Optimization of the form in which the sample is presented to the analysis method is obviously the price to pay for the ultimate sensitivity and information depth of S-SIMS.
\end{abstract}

Keywords Static SIMS - FT LMMS · Pigments · Molecular · Cultural heritage

\section{Introduction}

Paintings, frescoes, miniatures and illuminated manuscripts are an integral part of our cultural heritage. Some of the pigments used in these objects, including their arrangements, are characteristic of the period in which the work of art was created. They also provide information about the region where the pigments were purchased or produced, and in most cases, they provide the means to authenticate the work of art. Microscopic and molecular information about the nature and the distribution of pigments and binding media therefore enable us to answer technical questions about the history of art, such as the deciphering the original appearance of a painting, or establishing the optimum chemical and physical conditions required by

R. Van Ham · L. Van Vaeck · F. Adams

Department of Chemistry,

University of Antwerp,

2610 Antwerp, Belgium

\section{A. Adriaens $(\bowtie)$}

Department of Analytical Chemistry, Ghent University,

9000 Ghent, Belgium

e-mail: annemie.adriaens@ugent.be

Tel.: +32-9-2644826

Fax: $+32-9-2644960$ the work of art before conservation and restoration [1] The latter is necessary when deciding upon the correct treatment method used to conserve or restore the artefacts.

Several elemental analysis methods are currently exploited for the analysis of painted works of art, including X-ray fluorescence (XRF) and particle induced X-ray analysis (PIXE), while methods such as X-ray diffraction (XRD), Raman and static secondary ion mass spectrometry (S-SIMS) can also deliver specific molecular information [2-9].

One of the major advantages of S-SIMS resides in its potential ability to characterize and image both inorganic and organic analytes. It therefore represents one of the few methods capable of closing the traditional gap between the fields of organic and inorganic analytical chemistry. This capability has been demonstrated in work by the research group at AMOLF [10-12] for the study of paint crosssections.

In this study we have explored the ability of time-of-flight static secondary ion mass spectrometry (TOF S-SIMS) to characterize pure pigments and pigments in paint layers by providing molecular information. By retrieving molecular information on inorganic compounds, we intend to address the growing demand from scientific and technological research to specify the local composition of a sample in terms of molecules rather than elements. It is evident that the behavior and properties of bulk materials and interfaces between them are governed by the structures and the interactions of molecules.

Fourier transform laser microprobe mass spectrometry (FT LMMS) has also been used, as a complementary technique for exploring the potential benefits from probing the soft local energy regime during analysis, where no charge build-up occurs for insulating samples.

\section{Experimental}

Table 1 surveys a selection of commonly used inorganic pigments. Auripigment and verdigris (Kremer Pigments, Aichstetten, Germany) were used in this study as examples 
Table 1 Survey of a selection of inorganic pigments commonly used in art objects from different historical periods

\begin{tabular}{|c|c|c|c|}
\hline White pigments & & Green pigments & \\
\hline Lithopone & $\mathrm{ZnS}+\mathrm{BaSO}_{4}$ & Chromium oxide & $\mathrm{Cr}_{2} \mathrm{O}_{3}$ \\
\hline Baryte & $\mathrm{BaSO}_{4}$ & Cobalt green & CoO.nZnO \\
\hline Rutile & $\mathrm{TiO}_{2}$ & Emerald green & $\left(\mathrm{CH}_{3} \mathrm{COO}\right)_{2} \mathrm{Cu} \cdot 3 \mathrm{Cu}\left(\mathrm{AsO}_{2}\right)_{2}$ \\
\hline Lead white & $2 \mathrm{PbCO}_{3} \cdot \mathrm{Pb}(\mathrm{OH})_{2}$ & Malachite & $\mathrm{CuCO}_{3} \cdot \mathrm{Cu}(\mathrm{OH})_{2}$ \\
\hline Zinc white & $\mathrm{ZnO}$ & Verdigris & $\left(\mathrm{CH}_{3} \mathrm{COO}\right)_{2} \mathrm{Cu} \cdot 2 \mathrm{Cu}(\mathrm{OH})_{2}$ \\
\hline Chalk & $\mathrm{CaCO}_{3}$ & Blue pigments & \\
\hline Gypsum & $\mathrm{CaSO}_{4} \cdot 2 \mathrm{H}_{2} \mathrm{O}$ & Azurite & $2 \mathrm{CuCO}_{3} \cdot \mathrm{Cu}(\mathrm{OH})_{2}$ \\
\hline Red pigments & & Cobalt blue & $\mathrm{CoO} . \mathrm{Al}_{2} \mathrm{O}_{3}$ \\
\hline Vermilion & $\mathrm{HgS}$ & Smalt & $\mathrm{CoO} . \mathrm{nSiO}_{2}\left(+\mathrm{K}_{2} \mathrm{O}+\mathrm{Al}_{2} \mathrm{O}_{3}\right)$ \\
\hline Red ochre & $\mathrm{Fe}_{2} \mathrm{O}_{3} \cdot \mathrm{H}_{2} \mathrm{O}+$ clay + silica & Ultramarine & $\mathrm{Na}_{8-10} \mathrm{Al}_{6} \mathrm{Si}_{6} \mathrm{O}_{24} \mathrm{~S}_{2-4}$ \\
\hline Realgar & $\mathrm{As}_{2} \mathrm{~S}_{2}$ & Yellow pigments & \\
\hline Red lead & $\mathrm{Pb}_{3} \mathrm{O}_{4}$ & Auripigment & $\mathrm{As}_{2} \mathrm{~S}_{3}$ \\
\hline Black pigments & & Cadmium yellow & $\mathrm{CdS}$ \\
\hline Magnetite & $\mathrm{Fe}_{3} \mathrm{O}_{4}$ & Massicot & $\mathrm{PbO}$ \\
\hline \multirow[t]{3}{*}{ Ivory black } & $\mathrm{Ca}_{3}\left(\mathrm{PO}_{4}\right)_{2}+\mathrm{C}+\mathrm{MgSO}_{4}$ & Lead- tin yellow & $\mathrm{Pb}_{2} \mathrm{SnO}_{4}$ \\
\hline & & Lead antimonate yellow & $\mathrm{Pb}_{2} \mathrm{Sb}_{2} \mathrm{O}_{7}$ or $\mathrm{Pb}_{3}\left(\mathrm{SbO}_{4}\right)_{2}$ \\
\hline & & Yellow ochre & $\mathrm{Fe}_{2} \mathrm{O}_{3} \cdot \mathrm{H}_{2} \mathrm{O}$ \\
\hline
\end{tabular}

of pure pigments. They were pressed into pellets (diameter $1 \mathrm{~cm}$, thickness $1-2 \mathrm{~mm})$, using a common powder press at 6 ton $\mathrm{cm}^{-2}$.

Artificial paint layer samples were prepared at the Kunsthistorisches Museum (Vienna) and the Academy of Fine Arts (Vienna) according to information provided in historical sources. Prepolymerised linseed oil was used as binding medium for the paint, whereas the upper varnish layer consisted of mastic resin dissolved in oil of terpentine. Sample 1 contained six overlays: (1) gold foil; (2) cinnabar red (HgS); (3) red iron oxide paint layer $\left(\mathrm{Fe}_{2} \mathrm{O}_{3} . \mathrm{n}\right.$ $\left.\mathrm{H}_{2} \mathrm{O}\right)$; (4) lead-tin yellow paint layer $\left(\mathrm{Pb}_{2} \mathrm{SnO}_{4}\right)$; (5) azurite paint layer $\left(2 \mathrm{CuCO}_{3} \cdot \mathrm{Cu}(\mathrm{OH})_{2}\right)$; and (6) varnish. Paint fragments $\sim 1 \mathrm{~mm}^{2}$ and $\sim 0.1 \mathrm{~mm}$ thick were embedded in resin (Technovit $2000 \mathrm{LC}$, light curing) and polished to expose the cross-section at the surface. Sample 2 consisted of a blue $\mathrm{CuCO}_{3}$ paint layer with a white $\mathrm{ZnO}$ coating covered with varnish. Figure 1 shows light microscopy images of the two cross-sections.

SIMS analyses were performed with a TOF-SIMS IV (ION-TOF, Germany) instrument, equipped with an ion reflector. Analyses were performed using a $\mathrm{Ga}^{+}$liquid metal ion source operated at $25 \mathrm{kV}$ beam voltage under charge compensation. The choice of this beam was motivated by the ability to record both spectra and images.
Data for each powder were collected for $300 \mathrm{~s}$ with a raster of $300 \times 300 \mu \mathrm{m}^{2}$ using the $\mathrm{Ga}^{+}$primary ion beam. Data on the cross-sections of the paint layers were acquired over an area of $150 \times 150 \mu^{2}$ for $890 \mathrm{~s}$ with a total ion dose of $2.5 \times 10^{12}$ ions $\mathrm{cm}^{-2}$.

FT LMMS analyses were performed with an instrument developed at the University of Antwerp from a Spectrospin CMS 47X FTMS (Bruker Spectrospin, Billerica, MA, USA) [13]. The system uses an Infinity Cell TM [14] in a 4.7 $\mathrm{T}$ magnet with an external ion source where the ionization takes place. A frequency quadrupled Nd:YAG laser (Quanta Ray DCR 2-10, Spectra Physics, Mountain View, CA, USA) operated at a wavelength of $266 \mathrm{~nm}$ was mounted in reflection geometry ( $45^{\circ}$ incidence angle) in order to ionize the specimen. Details of the conversion are described elsewhere [15]. The spot diameter on the sample is $5 \mu \mathrm{m}$. The power density on the sample can be varied in the range $10^{6}$ to $10^{11} \mathrm{~W} \mathrm{~cm}^{-2}$. The region of interest is positioned for analysis in the waist of the laser under microscopical observation (magnification of $700 \times$ ). Ions are transported from the ion source by a home-made ion optical transfer line using static electrical fields [16]. The instrumental configuration only allows ions within a limited $m / z$ range to be trapped due to the so-called TOF effect, which is fully described elsewhere [17].
Fig. 1a-b Light microscopy images of the cross-sections of the two embedded paint fragments: a sample 1 and b sample 2

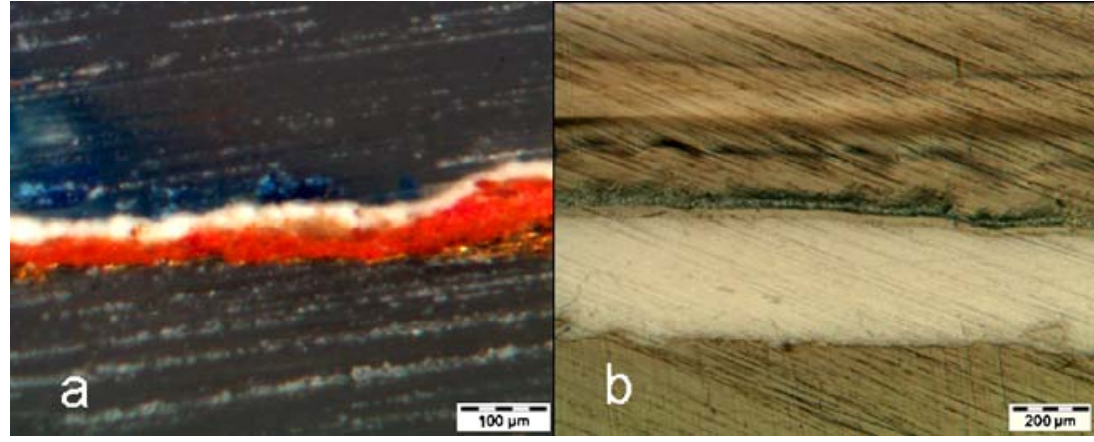




\section{Results and discussion}

Molecular speciation of pure pigments

SSIMS has emerged as a promising technique when it comes to obtaining molecule-specific information [18-23]. Its potential advantage here derives primarily from the use of a low flux ion bombardment resulting in relatively high molecular ion yields, although the ion yield may be much lower in comparison to elemental ions. The latter problem can be resolved by using a mass analyzer with high trans- mission, such as a time-of-flight mass spectrometer, which gives a good sensitivity. An other alternative would be to use polyatomic projectiles. These offer, in principle, significant potential to increase the molecular information in S-SIMS [20-23].

Positive and negative SIMS spectra from auripigment are shown in Fig. 2. Note that analytes containing arsenic generally do not yield elemental ions. The signals in both ion detection modes essentially refer to sulfide and oxide species or combinations of them. Although the composition is specified as $\mathrm{As}_{2} \mathrm{~S}_{3}$, it is well known that the pigment
Fig. 2 Positive (a) and negative (b) ion mass spectra from a pellet of auripigment
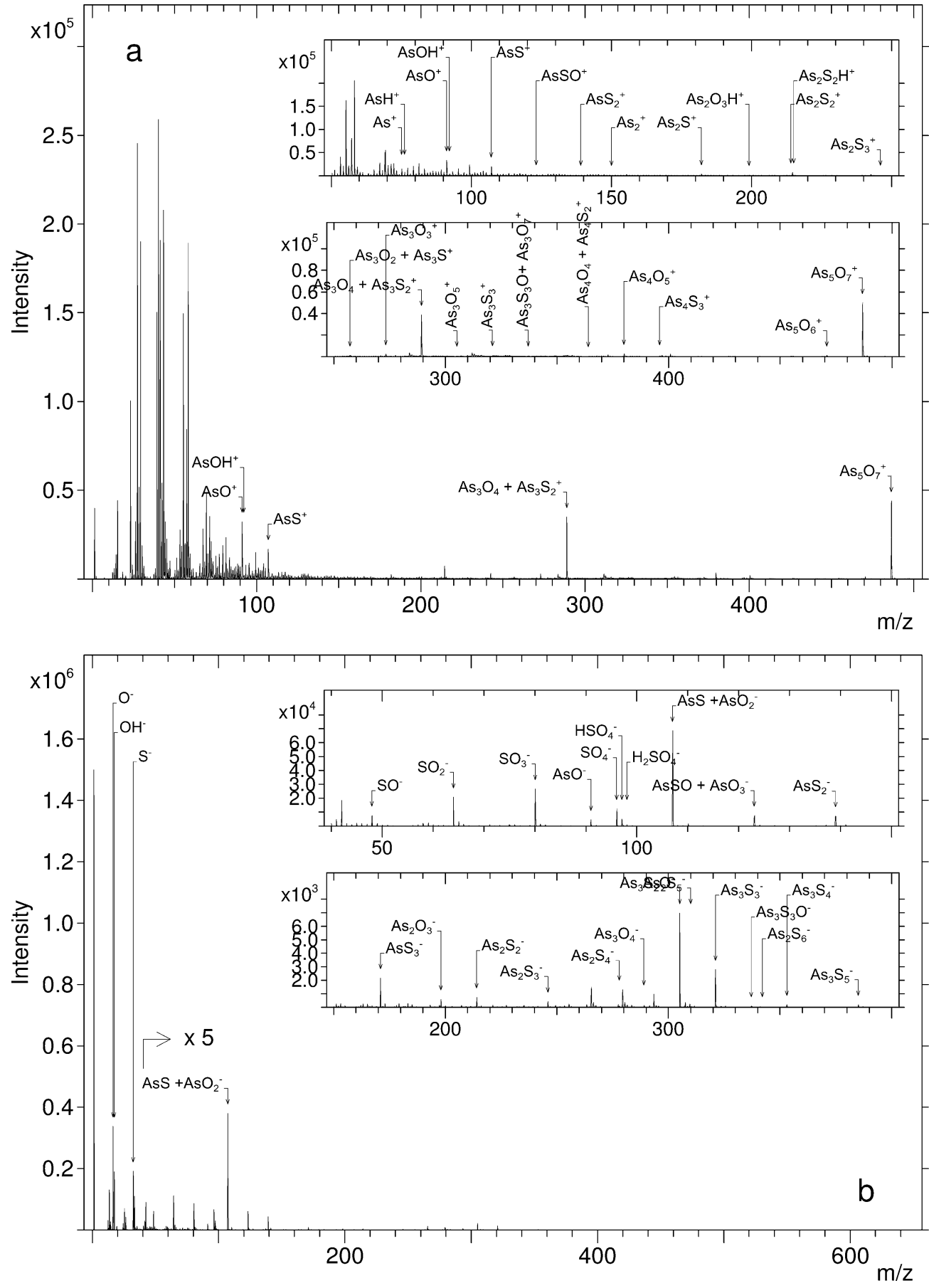
usually contains oxides. Distinguishing between the oxide and sulfide ions is not always feasible in the high $\mathrm{m} / \mathrm{z}$ range but the pattern of $\mathrm{As}_{\mathrm{n}} \mathrm{O}_{\mathrm{m}}{ }^{+}$and $\mathrm{As}_{\mathrm{n}} \mathrm{O}_{\mathrm{m}}{ }^{-}$is comparable to that observed in the spectra of $\mathrm{As}_{2} \mathrm{O}_{3}$ and $\mathrm{As}_{2} \mathrm{O}_{5} \cdot 3 \mathrm{H}_{2} \mathrm{O}$ [20].

The mass spectra of the verdigris, shown in Fig. 3, clearly demonstrate the acetate component of the pigment, which allows us to distinguish it from another commonly used green pigment, malachite, a copper carbonate $\left(\mathrm{CuCO}_{3} \cdot \mathrm{Cu}\right.$ $(\mathrm{OH})_{2}$ ). In the positive ion mode, the $\mathrm{CH}_{3}{ }^{+}$signal is un- usually intense and prevalent peaks refer to the monomeric and dimeric adducts (one or two analyte molecules attached to a stable ion). Interestingly, the detection of ions such as $\left(\mathrm{CH}_{3} \mathrm{COO}\right) \mathrm{Cu} . \mathrm{Cu}^{+}$refer to the presence of the $\mathrm{Cu}(\mathrm{I})$ form or its generation during primary ion bombardment. The corresponding intensity of the $\left(\mathrm{CH}_{3} \mathrm{COO}\right) \mathrm{Cu} \cdot \mathrm{Cu}^{+}$peak is lower than for the acetate-related ions. In the negative ion mode, the copper acetate component is detected as a molecular ion and as an adduct with acetate anions. The relative contribution of the oxide-related ions is rather limited.
Fig. 3 Positive (a) and negative (b) ion mass spectra from a pellet of verdigris
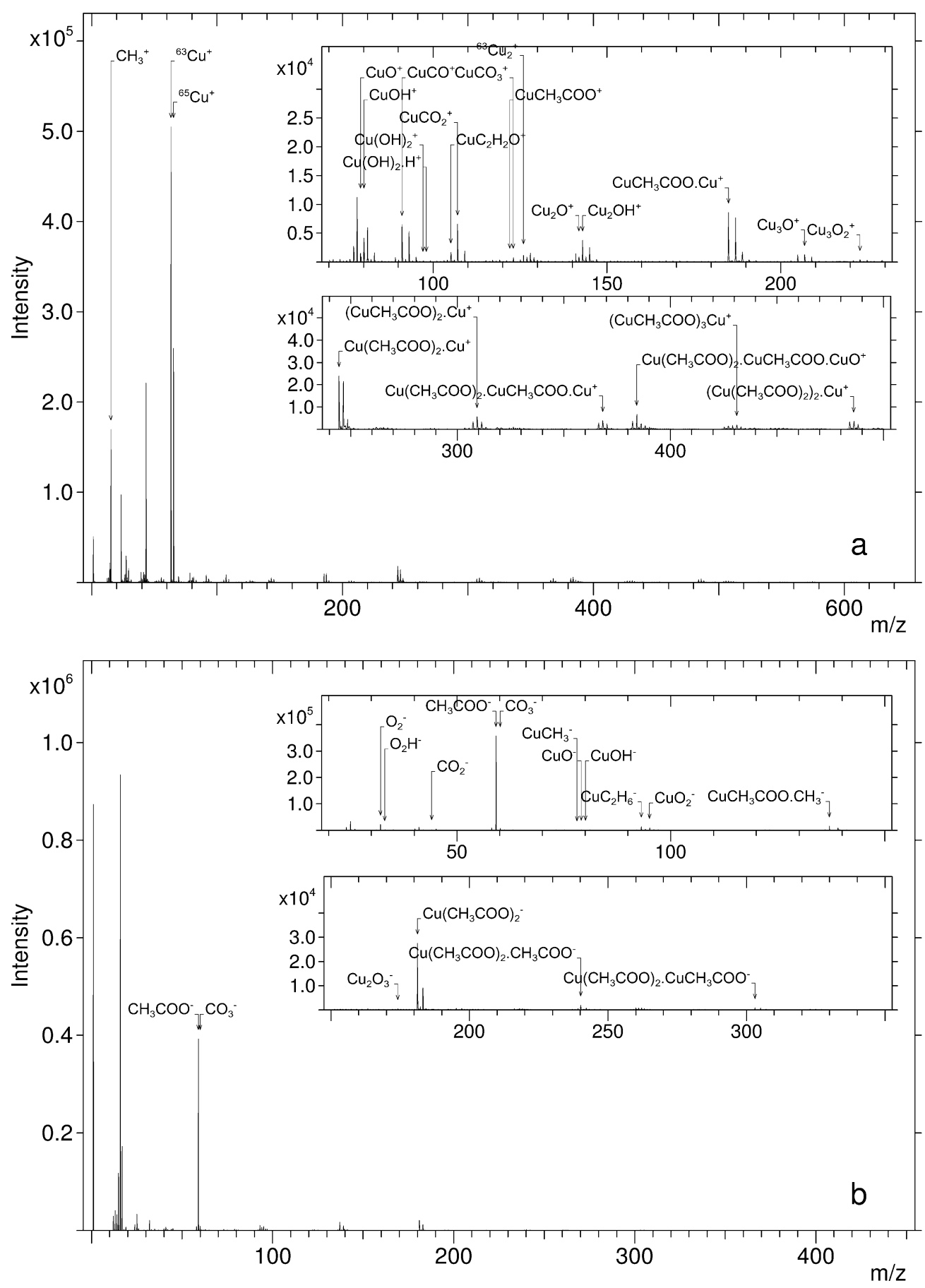
File: 1080301 SV.MIF

Pulses/Pixel: 32
Field of view. $150 \times 150 \mu \mathrm{m}^{2} \quad$ Scans: $1-17$ $\mapsto 20 \mu \mathrm{m}$
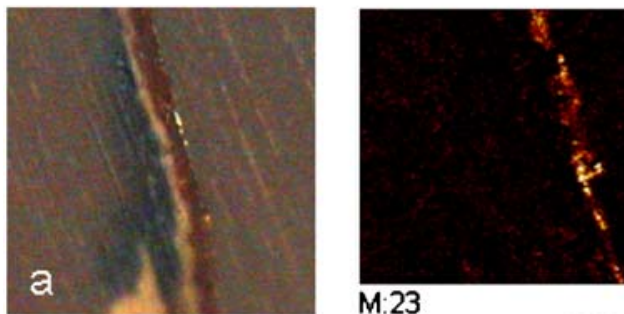

M:23
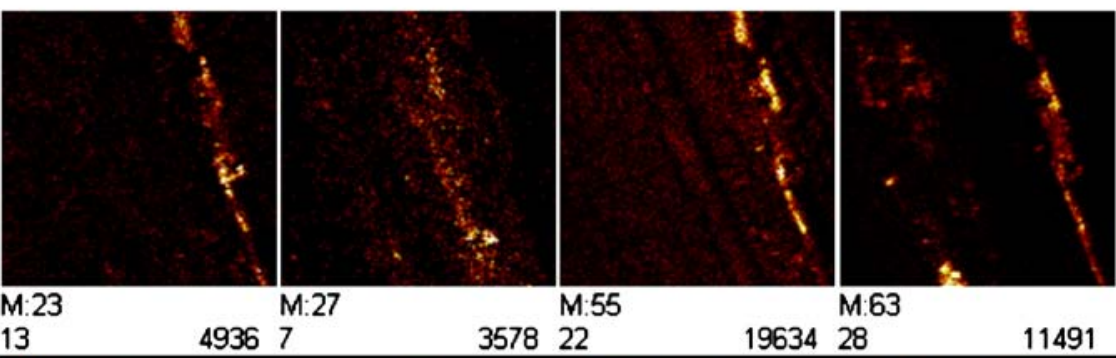

M:63

1963428

11491

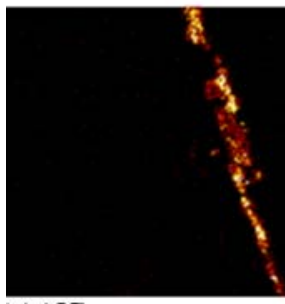

M:107

12

34643

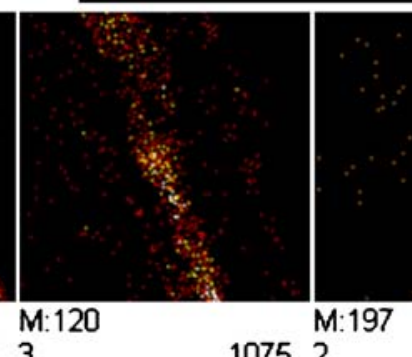

10752

Fig. 4 Light micrograph (a) and secondary ion images recorded from the embedded paint layer test sample 1 . The notation $M$ refers to the $m / z$ of $\mathrm{Na}^{+}(m / z 23), \mathrm{Al}^{+}(m / z 27), \mathrm{C}_{3} \mathrm{H}_{5}{ }^{+}\left(\mathrm{m} / z\right.$ 55), $\mathrm{Cu}^{+}(\mathrm{m} / z$

Characterization of paint fragments

in embedded layers

Figure 4 shows positive ion images of sample 1 together with a light microscopy image taken in the TOF S-SIMS instrument itself. Specifically, the gold layer is seen in the $\mathrm{m} / z 197$ image. Nevertheless $\mathrm{Ag}^{+}(\mathrm{m} / z$ 107) appears to be more abundantly generated from the same layer. The $\mathrm{Na}^{+}$ and $\mathrm{Cu}^{+}$images show an enrichment of the metallic layer while the organic ions at $\mathrm{m} / \mathrm{z} 55$ are also intensified. The next layer seems to be enriched with aluminum but ions from the red $\mathrm{HgS}$ pigment are not generated. The red iron oxide layer is also not visible. Both of these issues are the result of either charging or contamination problems. The lead-tin yellow coating is seen in the $\mathrm{Sn}^{+}$and $\mathrm{Pb}^{+}$images. As $\mathrm{Pb}_{2} \mathrm{SnO}_{4}$ consists of a mixture of $\mathrm{PbO}$ and $\mathrm{SnO}_{2}$, the $\mathrm{PbO} . \mathrm{H}^{+}$ions represent direct molecular information on a specific component. Intense $\mathrm{Cu}^{+}$ions identify the blue azurite layer. Images of ions at higher $\mathrm{m} / \mathrm{z}$ do not contain significant information.

Fig. 5 Light micrograph (a) and SI images (ten scans) recorded by TOF S-SIMS with $\mathrm{Ga}^{+}$primary ions from the embedded paint layer test sample 2. The notation $\mathrm{M}$ refers to the $m / z$ of $\mathrm{CH}_{3}^{+}(\mathrm{m} / \mathrm{z} 15), \mathrm{Cu}^{+}$ $\left(m / z\right.$ 63) and $\mathrm{Zn}^{+}(m / z 64)$
The light microscopy and selected ion images for the second sample are shown in Fig. 5. Again, mostly elemental ions are detected. The $\mathrm{Zn}^{+}$image allows the thick layer to be identified, while the copper pigment in the thin layer occurs in the form of local inclusions in the $10 \mu \mathrm{m}$ range. The bright vertical feature in the image of $\mathrm{m} / \mathrm{z} 15$ is tentatively associated with the binder used for the blue paint.

Sample 1 has also been analyzed by FT LMMS. The increased information depth $(10 \mathrm{~nm})$ in comparison to SSIMS does not hamper the analysis here since the crosssectioned paint fragments provide a deep enough sample with essentially the same composition. The required lateral resolution of about $20 \mu \mathrm{m}$ is well above the $5 \mu \mathrm{m}$ spot of FT LMMS.

Figure 6 illustrates representative cation mass spectra for each of the three layers examined (gold foil, lead-tin yellow and azurite). As in TOF S-SIMS, only elemental ions have been detected by FT LMMS. The first layer (a) yields $\mathrm{Cu}^{+}$, the second layer (b) shows the presence of $\mathrm{Pb}^{+}$and $\mathrm{Sn}^{+}$as

\section{File: W90301EV.MIF \\ Pulses/Pixel: 64}

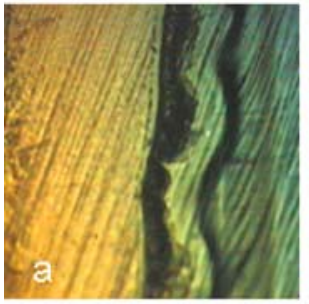

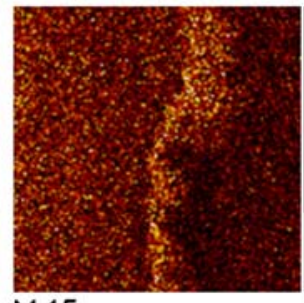

M:15

10
3370218
Field of view: $300 \times 300 \mu \mathrm{m}^{2}$ $\longmapsto 50 \mu \mathrm{m}$

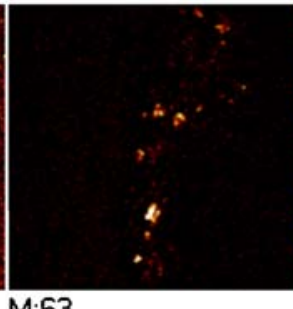

40729

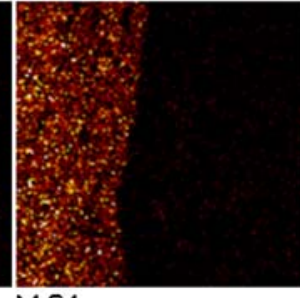

M:64 

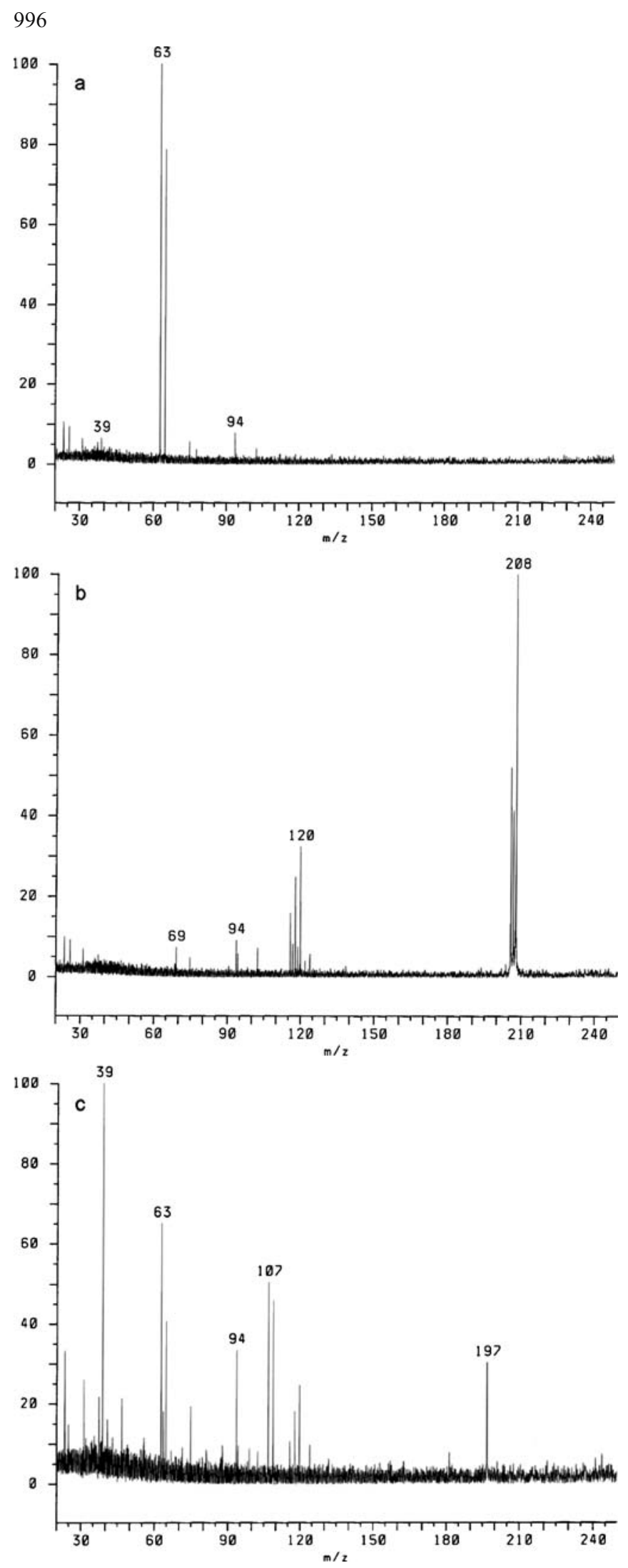

Fig. 6a-c Positive ion mass spectra recorded from the embedded paint sample 1 by FT LMMS from the azurite (a), lead-tin yellow (b), and gold layer (c) in Fig. 1 expected, while the third layer (c) produces signals from $\mathrm{K}^{+}$, $\mathrm{Cu}^{+}, \mathrm{Ag}^{+}$and $\mathrm{Au}^{+}$. The detection of $\mathrm{Sn}^{+}$in spectrum $\mathrm{C}$ is associated with cross-contamination between the layers. The sample position must be adjusted at a repetition rate of $1 \mathrm{~Hz}$ and accurate selection of one layer is not obvious because of the poor visibility. Improvement of the illumination system is desirable for such applications.

The mass spectra in FT LMMS are typically accumulated over 100 shots. The latter implies that a layer (lateral dimension $20 \mu \mathrm{m}$ ) is analyzed over a length of about $125 \mu \mathrm{m}$. In TOF SIMS, the surface is sampled from $20 \times 150 \mu \mathrm{m}^{2}$ (size of vertical feature). Hence, the area used for signal generation in both instruments is comparable. However, the typical crater depth in FT LMMS is 100 $300 \mathrm{~nm}$, while in principle TOF S-SIMS consumes only a fraction of the uppermost monolayer, although the subsurface is molecularly destroyed over, say, $50 \mathrm{~nm}$ and therefore should be considered to be "consumed" as well. This means that the sensitivities of both instruments are in the same range, at least for sufficiently thick layers.

Although FT LMMS provides a better intensity ratio of adducts over elemental ions than TOF S-SIMS for most inorganic analytes, no molecular information has been obtained from these samples. There are several reasons for this. Delicate tuning is the price to be paid for microanalysis with high mass resolution, while the sensitivity is similar to that in a TOF MS system. As a result, quite a few shots are required to optimize the voltages for each sample and the region of interest is rapidly consumed for these embedded paint fragments. In this respect, it would have been beneficial to analyze the outer layers of a unembedded sample.

\section{Conclusions}

The potential of TOF S-SIMS with $\mathrm{Ga}^{+}$primary ions to accurately characterize the pigments in microscopical samples from laboratory-made and medieval art objects has been studied. Specifically, embedded multilayer paint fragments have been characterized in cross-sectioned samples. Additionally, pigment particles recovered by rubbing a cotton tip over an ancient manuscript have been studied.

The paint fragments were prepared using ingredients and techniques given in historical sources. Prior investigation of typical pigments used, such as auripigment and verdigris, has allowed the detection of numerous high $\mathrm{m} / \mathrm{z}$ ions for molecular identification. However, in the embedded paint fragment, image information was only obtained for elemental ions from the pigments (not even all of them) and low $\mathrm{m} / \mathrm{z} \mathrm{HC}$ ions from the embedding medium. In our opinion, the main reason was the sample preparation, which yielded the paint fragment in the middle of a relatively large and thick cube of nonconductive resin. The resulting charge build-up is significant, and in our experience this is detrimental to the generation of high $\mathrm{m} / \mathrm{z}$ ions. Complementary experiments with FT LMMS have confirmed the results, and no additional molecular information has been obtained. The specimen preparation is not ade- 
quate here either. The sensitivities of both instruments appear to be very similar, as calculated on the basis of the signal intensities in comparison to the consumed or damaged sample volume.

The manuscript pigment particles were transferred from the cotton tip to a more suitable silicon substrate. This was later shown to be a far from ideal procedure for subsequent analysis by TOF S-SIMS. Localization of the particles of interest within the numerous cotton fibres is problematic, and contamination of the pigment particles is likely to occur. No molecular information was obtained and even elemental ion detection was limited.

The results essentially illustrate the need for better sample preparation procedures. As analytical procedures become more sensitive and refined, "common" procedures for sampling and specimen handling become less adequate. In particular, in methodologies designed for analysis of asreceived samples, it is common to expect progress from new instrumental developments, but it often turns out that much more attention needs to be paid to basic operations in order to make the sample compatible with the instrumental technique. This has been confirmed in a study by Van Loon et al., who has emphasized the importance of correct surface preparation when performing imaging analytical studies [24].

Acknowledgements The authors are grateful to P. Vandenabeele (Ghent University, Belgium) for kindly providing the pigments. M. Griesser (Kunsthistorisches Museum, Vienna) and M. Schreiner (Academy for Fine Arts, Vienna) are thanked for kindly making the paint layer cross-sections available. COST Action G8 is acknowledged.

\section{References}

1. Keune K (2005) Binding medium, pigments and metal soaps characterized and localized in paint cross-sections. Dissertation, Molart Report. Archetype, London

2. Creagh DC, Bradley DA (eds) (2000) Radiation in art and archaeology. Elsevier, Amsterdam

3. Ciliberto E, Spoto G (eds) (2000) Modern analytical methods in art and archaeology. Wiley, New York

4. Demortier G, Adriaens A (eds) (2000) Ion beam study of art and archaeological objects, EUR 19218. Office for the Official Publications of the European Union, Luxembourg
5. Janssens K, Van Grieken R (eds) (2004) Non-destructive microanalysis of cultural heritage materials. Elsevier, Amsterdam

6. Townsend J, Eremin K, Adriaens A (eds) (2003) Conservation science 2002. Archetype, London

7. Adriaens A, Degrigny C, Cassar J (eds) (2005) Benefits of nondestructive analytical techniques for conservation, EUR 21636. Office for the Official Publications of the European Union, Luxembourg

8. Bitossi G, Giorgi R, Mauro M, Salvadori B, Dei L (2005) Appl Spectrosc Rev 40(3):187-228

9. Van Grieken R, Janssens K (eds) (2005) Cultural heritage conservation and environmental impact assessment by nondestructive testing and micro-analysis. Taylor and Francis Group, London

10. Boon JJ, Keune K, van der Weerd J, Geldof M, van Asperen de Boer JRJ (2001) Chimia 55:952-960

11. Van der Weerd J, Boon JJ, Geldof M, Heeren RMA, Noble P (2002) Zeitschrift Kunsttechnologie Konservierung 16:35

12. Keune K, Boon JJ (2004) Anal Chem 76(5):1374-1385

13. Grossmann P, Caravatti P, Allemann M, Kellerhals HP (1988) In: Proc 36th ASMS Conf on Mass Spectrometry and Allied Topics, 5-9 June 1988, San Francisco, pp 616-617

14. Caravatti P, Alleman M (1991) Org Mass Spectrom 26:514518

15. Van Vaeck L, Van Roy W, Struyf H, Adams F, Caravatti P (1993) Rapid Comm Mass Spectrom 7:323-331

16. Van Vaeck L, Van Espen P, Gijbels R, Baykut G, Laukien FH (2000) Eur J Mass Spectrom 6:277-287

17. Struyf H, Van Roy W, Van Vaeck L, Van Grieken R, Gijbels R (1993) Anal Chim Acta 283:139-151

18. Van Ham R, Van Vaeck L, Adams F, Adriaens A (2003) Anal Chim Acta 500:259-278

19. Van Ham R, Van Vaeck L, Adams F, Adriaens A (2004) Anal Chem 76(9):2609-2617

20. Cuynen E, Van Vaeck L, Van Espen P (1999) Rapid Comm Mass Spectrom 13(23):2287-2301

21. Van Ham R, Van Vaeck L, Adams F, Adriaens A (2005) J Anal Atom Spectrom 20(10):1088-1094

22. Van Ham R, Van Vaeck L, Adriaens A, Adams F, Hodges B, Groenewold G (2002) J Anal Atom Spectrom 17(8):753-758

23. Van Ham R, Van Vaeck L, Adriaens A, Adams F, Hodges B, Appelhans A, Groenewold G (2005) Int J Mass Spectrom 247:28-36

24. Van Loon A, Keune K, Boon J (2005) In: Parisi C, Buzzanca G, Paradisi A (eds) Proc 8th International Conf on Non-Destructive Investigations and Microanalysis for the Diagnostics and Conservation of the Cultural and Environmental Heritage, 1519 May 2005, Lecce, Italy. Italian Society of Non-Destructive Testing Monitoring Diagnostics, Rome, p 89 